\title{
A PANEL DATA ANALYSIS ON FACTORS AFFECTING MARKET DOMINANCE IN THE TURKISH BANKING SECTOR
}

DOI: 10.17261/Pressacademia.2021.1535

PAP- V.14-2021(57)-p.184-185

Sami Kucukoglu ${ }^{1}$, Elif Guneren Genc ${ }^{2}$

${ }^{1}$ Istanbul Commerce University, Institute of Finance, Financial Econonmics, Istanbul, Turkey. samikucukoglu@yahoo.com, ORCID: 0000-0002-0739-2196

${ }^{2}$ Istanbul Commerce University, Faculty of Business, Department of Aviation Management, Istanbul, Turkey. elifg@ticaret.edu.tr, ORCID: 0000-0001-5439-914X

To cite this document

Kucukoglu, S., Guneren Genc, E., (2021). A panel data analysis on factors affecting market dominance in the Turkish banking sector. PressAcademia Procedia (PAP), 14, 184-185.

Permanent link to this document: http://doi.org/10.17261/Pressacademia.2021.1535

Copyright: Published by PressAcademia and limited licensed re-use rights only.

\section{ABSTRACT}

Purpose- In this study, it is aimed to determine the factors affecting market dominance in the banking sector of 37 banks operating in the Turkish banking sector between 1997-2020. The market size of each bank was calculated on a yearly basis for the banks examined in the period determined in the study, and all the data belonging to the independent variables used in the analysis were standardized on a yearly basis and specific to each bank. In the results obtained, it has been examined whether the variables affecting market dominance in the Turkish banking sector are econometrically significant or not. The main motivation of the research is to contribute to the literature by making an original study on the determination of the variables affecting the market dominance in the Turkish banking sector.

Methodology- After the literature review on the method and the subject, the data set of 37 banks operating in the 1997-2020 period, obtained from the Banks Association of Turkey (TBB), was analyzed using panel data regression models. When the data set created for the applied panel data analysis method was examined, it was determined that there was cross-section dependence and varying variance, but no autocorrelation. In this context, the parameters estimated from the prais-winsten regression using the soft generalized least squares method were used for the analysis.

Findings- In the findings obtained as a result of the analysis, it has been determined that there are econometrically significant variables that affect the market dominance rate in the Turkish banking sector.

Conclusion- As a result of the study, it was seen that the factors affecting the market dominance in the Turkish banking sector, the total deposits and total equity items in the liabilities (debt) side of the bank balance sheets decreased the market dominance rate, while the number of branches and employees increased. The fact that the total loans included in the balance sheet assets (credit) have a decreasing effect on the market dominance can be explained because each bank has legally required reserves for the loan given.

Keywords: Banking, finance, market dominance, panel regression, panel data

JEL Classification: G21, C33

\section{TÜRK BANKACILIK SEKTÖRÜNDE PIYASA HAKIMIYETINE ETKI EDEN FAKTÖRLER ÜZERINE BÍR PANEL} VERI ANALizi

\section{ÖZET}

Amaç- Bu çalışmada, Türk bankacılık sektöründe 1997-2020 dönemi arasında faaliyet gösteren 37 bankanın, bankacılık sektöründe piyasa hakimiyetine etki eden faktörlerinin belirlenmesi amaçlanmıştır. Çalışmada belirlenen dönemde incelenen bankalar için yıl bazında her bankanın piyasa büyüklüğü hesap edilmiş ve analizde kullanılan bağımsız değişkenlere ait verilerin hepsi yıl bazında ve her bankaya özgü olacak şekilde standardize edilmiştir. Elde edilen sonuçlarda Türk bankacılık sektöründe, piyasa hakimiyetine etki eden değişkenlerin ekonometrik açıdan anlamlı olup, olmadığı incelenmiştir. Araştırmanın temel motivasyonu Türk bankacılık sektöründe piyasa hakimiyetine etki eden değişkenlerin belirlenmesi hususunda özgün bir çalışma yaparak literatüre katkı sağlamaktır.

Yöntem- Konuya ilişkin literatür taramasının ardından Türkiye Bankalar Birliği (TBB) kurumundan elde edilen 1997-2020 döneminde faaliyet gösteren 37 bankanın veri seti, panel veri regresyon modelleri kullanılarak analiz edilmiştir. Uygulanan panel veri analiz yöntemi için oluşturulan veri seti incelendiğinde yatay kesit bağımlılığı ve değişen varyans olduğu ancak otokorelasyon olmadığı tespit edilmiştir. Bu 
bağlamda analiz için, esnek genelleştirilmiş en küçük kareler yönteminin kullanıldığı prais-winsten regresyonundan tahmin edilen parametreler kullanılmıştır.

Bulgular- Analiz sonucunda elde dilen bulgularda, Türk bankacılık sektöründe, piyasa hakimiyeti oranını etkileyen ekonometrik açıdan anlamlı değişkenlerin varlı̆̆ı tespit edilmiştir.

Sonuç- Çalışmanın sonucunda Türk bankacılık sektöründe piyasa hakimiyetine etki eden faktörlerin, banka bilançolarında pasif (borç) tarafında bulunan toplam mevduat ve toplam öz kaynak kalemlerinin piyasa hakimiyet oranını azalttığı, şube ve çalışan sayısının ise arttırdı̆̆ı görülmüştür. Bilanço aktifinde (alacak) yer alan toplam kredilerin ise piyasa hakimiyet oranını azaltıcı etkide bulunması ise her bankanın verdiği kredi için yasal olarak zorunlu karşılık bulundurması sebebiyle açıklanabilir.

Anahtar Kelimeler: Bankacilık, finans, piyasa hakimiyeti, panel regresyon, panel veri

JEL Kodları: G21, C33

\section{KAYNAKLAR}

Aydın, Y. (2019). Türk Bankacılık Sektöründe Karlılığı Etkileyen Faktörlerin Panel Veri Analizi ile İncelenmesi. Gümüşhane Üniversitesi Sosyal Bilimler Enstitüsü Elektronik Dergisi, 10(1), 181-189.

Baltagi, B. (2005). Econometric Analysis of Panel Data. West Sussex: John Wiley \& Sons, Ltd.

Bayraktutan, Y., \& Demirtaş, I. (2011). Gelişmekte olan ülkelerde cari açığın belirleyicileri:Panel veri analizi. Kocaeli Üniversitesi Sosyal Bilimler Enstitüsü Dergisi 2(22), 1-28.

Bulut, E., \& Yenipazarlı, A. (2020). Endüstri 4.0 ve Teknolojinin İstihdam Üzerindeki Etkisi, Panel Veri Analizi. Pamukkale Journal of Eurasian Socioeconomic Studies, 15-35.

Çalışkan, Z. (2009). OECD ülkelerinde sağlık harcamaları: Panel veri analizi. Erciyes Üniversitesi ktisadi ve dari Bilimler Fakültesi Dergisi, sayı 34, 117-137.

Dedebek, E., \& Meriç, M. (2015 Sayı 97). Avrupa Birliği ülkelerinde savunma harcamalarını belirleyen ekonomik ve sosyal faktörler:Panel veri analizi. Sayıştay Dergisi, 89-104.

Demirci, N. (2017). İmalat Sanayi Sektöründe Kârlılığın Belirleyicileri: TCMB Sektör Bilançolarıyla Panel Veri Analizi. Ege Akademik Bakis 17(3), 381-394.

Güriş, S. (2015). Panel Veri ve Panel Veri Modelleri. İstanbul: Der Yayınları.

Güriş, S. (2018). Uygulamalı Panel Veri Ekonometrisi. İstanbul: Der Yayınları.

Güriş, S., \& Kızılarslan, Ş. (2017). Dengesiz Panel Veri Modeli ile EM Algoritması Sonuçlarının Karşılaştırılması. Marmara Üniversitesi Öneri Dergisi, $15-30$

Güriş, S., \& Özkaya, H. (2019). Gelışmekte olan ülkelerde tasarrufları etkıleyen faktörler: Panel veri analizi. Finansal Araştırmalar ve Çalışmalar Dergisi 11(20), 93-108.

Nargeleçekenler, M. (2009). Makroekonomik ve finansal serilerin ekonometrik analizi: Panel veri yaklaşımı Doktora Tezi. Bursa: Uludağ Üniversitesi Sosyal Bilimler Enstitüsü Ekonometri Anabilim Dalı Ekonometri Bilim Dalı.

Okuyan, H. (2013). Türkiye'deki En Büyük 1000 Sanayi İşletmesinin Karlılık Analizi. Business and Economics Research Journal 4(2), 23-36.

Tatoğlu, F. Y. (2013). İleri Panel Veri Analizi Stata Uygulamalı. İstanbul.: Beta Yayınları.

TBB/a. (2021, 09 30). İstatistiki Raporlar. www.tbb.org.tr: https://www.tbb.org.tr/tr/bankacilik/banka-ve-sektor-bilgileri/istatistikiraporlar/59 adresinden alınd

TBB/b. (2021, 06 10). Faaliyet Gösteren Bankalar. www.tbb.org.tr:

https://www.tbb.org.tr/Content/Upload/Dokuman/1360/Faaliyet_Gosteren_Bankalar.xlsx adresinden alındı

TBB/c. (2021, 06 10). Faaliyeti Sona Eren Bankalar. www.tbb.org.tr:

https://www.tbb.org.tr/Content/Upload/Dokuman/1362/Faaliyeti_Sona_Eren_Bankalar.xlsx adresinden alındı

Topaloğlu, E. (2017). Bankalarda Finansal Kırılganlığı Etkileyen Faktörlerin Panel Veri Analizi ile Belirlenmesi. Eskişehir Osmangazi Üniversitesi iiBF Dergisi 13(1), 15-38.

Wooldridge, J. M. (2015). Introductory Econometrics: A Modern Approach. Toronto: Nelson Education. 